\title{
THREE-DIMENSIONAL ASSESSMENT OF SKELETAL FROG APPLIANCE OUTCOMES VIA CONE BEAM COMPUTERIZED TOMOGRAPHY
}

\author{
${ }^{1}$ Ibrahim M Negm, ${ }^{2}$ Riyad A Iskander, ${ }^{3}$ khaled Aboulazm
}

Objective: To assess the three-dimensional effect of the mini-screw supported palatal distalizer the Skeletal Frog appliance via the aid of the cone-6eam computed tomography(CBCT) images. Methods: This study was conducted on twenty five subjects (9 boys and 16 girls), aged 13 to 15.2 years (average, 14.5 years) who exhibited Angle Class II division 1 malocclusion with the maxillary second molars fully erupted. CBCT were obtained prior treatment and post-distalization for all subjects. CBCT images were used to measure the skeletal, dental, and soft tissue changes. Paired-sample t-test was implemented to compare the mean difference between the pretreatment and post-distalization variables. Results: The maxillary first molars were efficaciously distalized, distally tipped, and intruded by $4.14 \mathrm{~mm}, 9.02^{\circ}$, and $2.03 \mathrm{~mm}$ ( $p £ 0.05)$ respectively. The maxillary right and left first molar exhibited significant rotation $4.33^{\circ}$ and $4.83^{\circ}$ ( $p £ 0.05$ ) respectively. Whereas the maxillary inter-molar and inter-premolar widths increased by $2.41 \mathrm{~mm}$ and $0.8 \mathrm{~mm}$ respectively. Regarding the maxillary first and second premolars they revealed a distalization of $1.89 \mathrm{~mm}$ and $2.8 \mathrm{~mm}$ (p£ 0.05$)$ respectively, with insignificant extrusion. The maxillary central incisors showed a statistically insignificant decrease in the anteroposterior position. Whereas the interincisal angle revealed a statistically significant increase by $3.24^{\circ}$ ( $p £ 0.05$ ). Conclusion: The Skeletal Frog appliance efficaciously distalizes the maxillary molars with the second molars fully erupted while providing absolute skeletal anchorage.

\section{Introduction}

One of the most frequently encountered orthodontic problems is class II malocclusions.
In growing individuals with class II malocclusions generally there are two main treatment strategies, either extraction or nonextraction. Recently there is a paradigm shift towards non-extraction which is more acceptable for both the patient and the orthodontist $^{1,2,3}$. In class II with mild to moderate crowding in the maxillary arch and normal mandibular arch the possible treatment approaches are, interproximal reduction, expansion, derotation and/or uprightening of posterior teeth, and maxillary molar distalization ${ }^{4,5}$

Currently there is an increasing trend directed towards distalization mechanics. Distalization allows the correction of; increased overjet, molar and canine relationship, lip profile, as well as facilitating space regaining via various retraction techniques ${ }^{6,7}$. Various noncompliance dependent alternatives for maxillary molar distalization are the fixed intraoral distalizers, which might be positioned either buccally or palatally or both. Among these devices are, Hilgers pendulum appliance, distal jet, Jones Jig, NiTi coil spring, Keles slider, first class appliance, repelling magnets, K-loop, Wilson distalizing arches, and Walde frog appliance ${ }^{8,910}$.

Yet, numerous side effects have been associated with these tooth-borne distalizers. Among which are molar tipping and extrusion, anchorage compromise such as, mesial migration of the premolars and flaring of incisors, in addition to the possibility of

\footnotetext{
${ }^{1}$ Assistant Professor of Orthodontics, Faculty of Dentistry, Ain Shams University, Cairo, Egypt.

${ }^{1} \mathrm{PhD}$ Department of Orthodontics, Faculty of Dentistry, Ain Shams University, Cairo, Egypt.

3Assistant Professor of Orthodontics, Faculty of Dentistry, Pharos University, Alexandria, Egypt.
} 
significant molar relapse $e^{4,7,10}$. Combining intraoral palatal distalizers with mini-screws (TADs) is gaining more popularity due to the TADs ease of insertion and removal, ability of immediate loading, small size, versatility, reduced invasiveness, variety of placement sites, and low cost $\mathrm{t}^{4,10,11 \text {, }}$.

When combining mini-screws with a palatal molar distalizer, paramedian placement of TADs is the most suitable region due to the decrease probability of root damage as well as the unnecessary need to reposition the miniscrews during retraction of the premolars and incisors $^{12,13,14,15,16}$.

Ludwig et al. ${ }^{17}$, designed the skeletal frog which is an innovative mini-screw supported maxillary molar distalization appliance which requires neither dental support nor an acrylic palatal button. This appliance is simple, hygienic, easily fabricated, effective in molar distalization, and without undesirable side effects ${ }^{17}$.

Thus, the aim of this study was to assess the three-dimensional effect of the mini-screw supported palatal distalizer the skeletal frog appliance which to the best of our knowledge has not been conducted utilizing the cone-beam computed tomography (CBCT).

\section{Materials and Methods}

Sample

This study was conducted on twenty five healthy Egyptian subjects selected and treated at the outpatient clinic of the Orthodontic Department, Faculty of Dentistry, Ain Shams University.

Power analysis revealed that a sample of 19 subjects will achieve a statistical power of approximately $80 \%$ at a significance level of 0.05 . The sample size was increased to involve 25 subjects to compensate for any withdrawals. Therefore, 25 subjects ( 9 boys and 16 girls), aged 13 to 15.2 years (average, 14.5 years), were included in this study. The inclusion criteria was as follows: Angle Class II division 1 malocclusion with a bilateral Class II molar relationship, permanent dentition with fully erupted second molars, skeletal class 1 with an ANB angle of $\left(0^{\circ}-4^{\circ}\right)$, normal or horizontal growth pattern $\left(\mathrm{SN} / \mathrm{GoGn}, 32^{\circ} \pm 6^{\circ}\right)$, mild to moderate crowding within the maxillary arch (4-6 mm), well aligned to mild crowding within the mandibular arch $(0-2 \mathrm{~mm})$, and no history of previous orthodontic treatment. Whereas the exclusion criteria involved; poor oral hygiene, congenitally missing permanent teeth, periodontal disease, and systemic disease or syndromes that might influence orthodontic treatment.

The study protocol was revised, modified, and approved by the local ethics committee, Faculty of Dentistry, Ain Shams University (approval no. FDASU REC ID 031216). Before commencing with treatment all subjects and their guardians signed an informed consent after receiving a detailed explanation of the treatment procedures and protocol.

Appliance fabrication and activation

All subjects had a full set of pretreatment and post-distalization diagnostic records including; diagnostic sheets, study casts, photographs, and CBCTs. The Skeletal Frog appliance in this study consisted of appropriate size bands on upper first molars with a welded lingual sheath, frog screw, 0.032 inch stainless steel distalizing springs, and hex key screw-driver (Forestadent, Pforzheim, Germany), in addition to two palatal TADs (infinitas, DB Orthodontics, UK).

The TADs were $2 \mathrm{~mm}$ in diameter, $6 \mathrm{~mm}$ in length, long neck, and self-drilling. They were positioned antero-posteriorly $6 \mathrm{~mm}$ posterior to the incisive papillae along the line connecting the mesial contact points of the first premolars. Whereas in the transverse plane they were placed paramedian $3 \mathrm{~mm}$ from the midpalatal suture. The correct position of the TADs was 
guided by a vacuum splint fabricated on a study cast.

Abutments were placed on the TADs followed with an impression with silicon rubber base, these abutments allow direct connection of the TADs to the distalizing screw body. The two transfer TADs were positioned on the abutments which was poured with dental stone to obtain working cast. Then, the fitted abutments on the working cast were soldered to the anterior tabs of the distalizing screw (Figure 1a).

The distalizing screw was positioned according to the following points; horizontally parallel to occlusal plane with a clearance of 10-12 mm from the cusp tips of the first molars close to their center of resistance, transversally along the midpalatal raphe, and antero-posteriorly the distal end of distalizing screw flushed with the mesial aspect of the lingual sheaths on the first molar bands (Figure 1b).

Finally the end section of the distalizing spring was bent $15^{\circ}$ towards the occlusal plane to counteract the molar distal tipping. The distalizing springs were preactivated with a distal force magnitude of $250 \mathrm{gm}$. In the patients mouth, the distalizing springs were tied to the lingual sheaths of the molar bands, and the abutments were tied to the TADs heads with stainless steel ligature wire (Figure 1c).

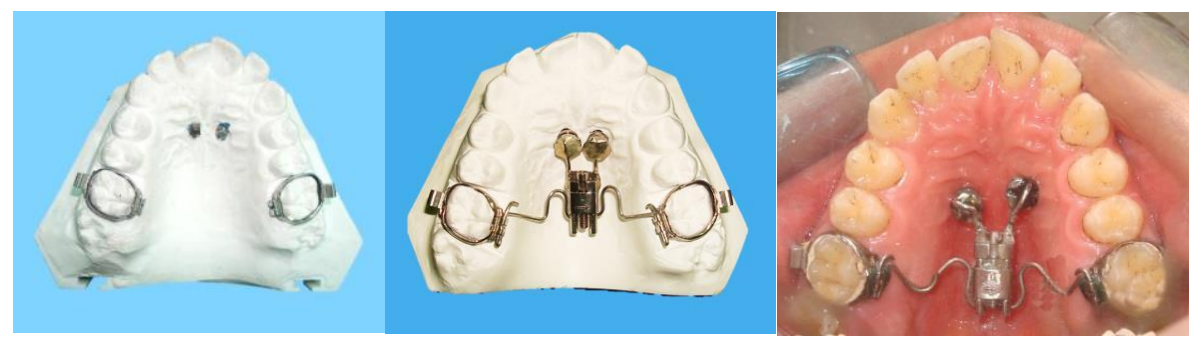

Figure 1. a) Transfer mini-screws on the working cast, b) Skeletal Frog appliance assembly on the working cast, c) Skeletal Frog appliance intraoral

According to Walde every $360^{\circ}$ turn of the screw opens the body by $0.4 \mathrm{~mm}$. Therefore, our reactivation protocol was three to five turns of the screw every four to five weeks which would lead to $1-2 \mathrm{~mm}$ of molar distalization per month. Reactivation was performed until a full bilateral class I molar relationship was attained (Figure 2).
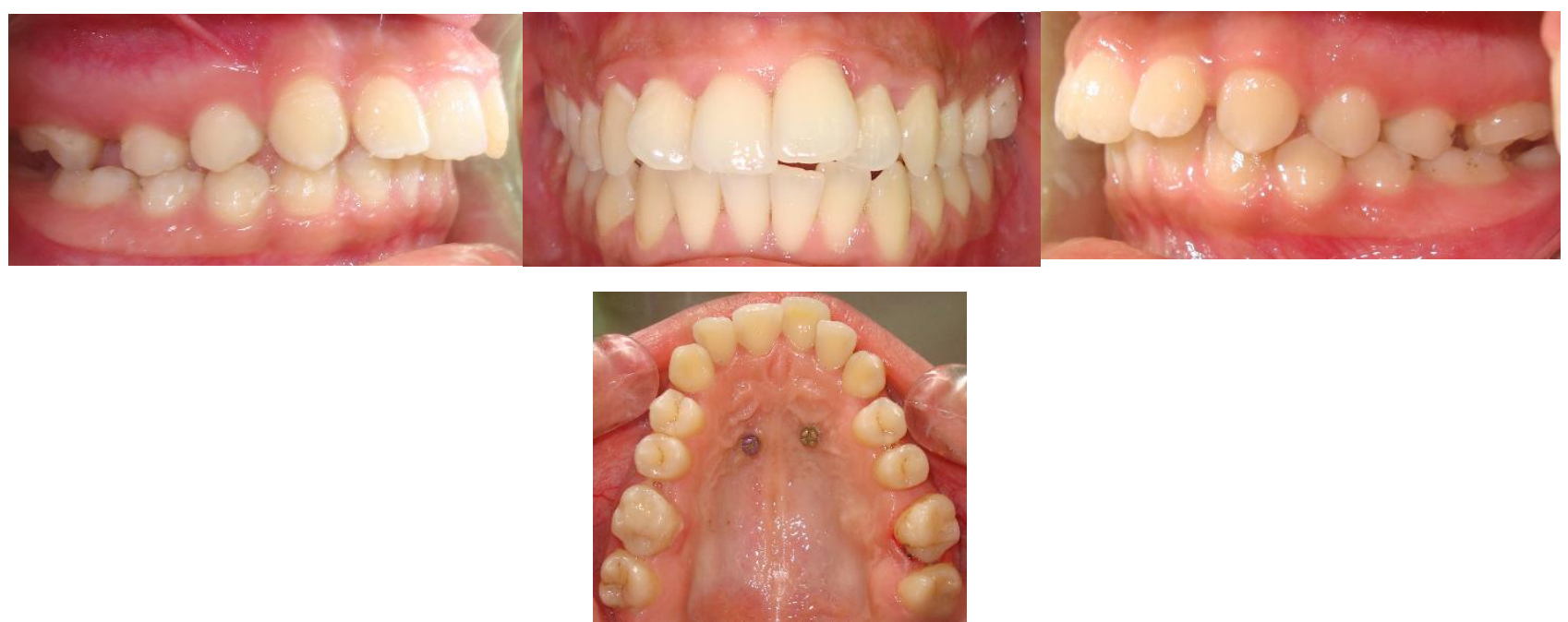

Figure 2. Intraoral right, frontal, left, and occlusa I views post-distalization 


\section{Evaluation}

Assessment of the 3D treatment effects of the Skeletal Frog appliance was performed by using the CBCT scans (SCANORA 3Dx, Soredex, Tuusula, Finland) pretreatment (T1) and post-distalization (T2) for each subject. The CBCT images were then uploaded to the software (Anatomage, version 5.01, San Jose, USA). All linear and angular measurements for the skeletal, dental, and soft tissue variables were obtained directly from the CBCT 3D volumetric images (Figure 2). The variables details and measurements are listed in (Table 1). All bilateral skeletal, and dental landmarks were digitized for left and right side independently and an average value was taken. The measurements were performed twice by the same practitioner, with an interval of 2 weeks between them.

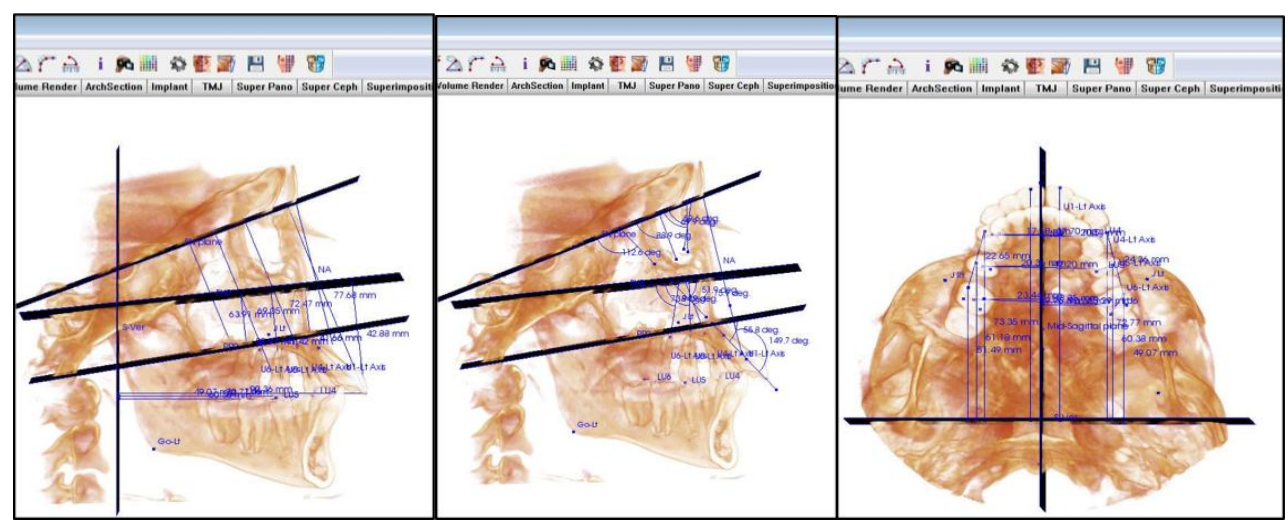

Figure 2. a) Sagittal linear measurements b) Sagittal angular measurements c) Axial linear measurements

Table 1. Variables for skeletal, dental, and soft tissue abbreviations and landmarks

\begin{tabular}{|c|c|}
\hline $\begin{array}{l}\text { Skeletal } \\
\text { Sagittal }\end{array}$ & \\
\hline $\operatorname{SNA}\left({ }^{\circ}\right)$ & Sella-nasion-A point \\
\hline $\operatorname{SNB}\left({ }^{\circ}\right)$ & Sella-nasion-B point \\
\hline $\mathrm{ANB}\left({ }^{\circ}\right)$ & A point-nasion-B point \\
\hline N-Pog-FHP $\left(^{\circ}\right)$ & Nasion pogonion to Frankfort horizontal plane \\
\hline \multicolumn{2}{|l|}{ Vertical } \\
\hline ANS-Me (mm) & Lower anterior facial height \\
\hline MP-PP $\left({ }^{\circ}\right)$ & Mandibular plane to palatal plane \\
\hline OP-PP $\left({ }^{\circ}\right)$ & Occlusal plane to palatal plane \\
\hline $\mathrm{OP}-\mathrm{MP}\left({ }^{\circ}\right)$ & Occlusal plane to mandibular plane \\
\hline \multicolumn{2}{|l|}{ Coronal } \\
\hline J R-J L (mm) & Linear distance from jugal right to jugal left (maxillary width) \\
\hline \multicolumn{2}{|l|}{ Dental } \\
\hline \multicolumn{2}{|l|}{ Upper first molar } \\
\hline U6-S Ver (mm) & $\begin{array}{l}\text { The distance from mesiobuccal cusp tip of upper right first } \\
\text { permanent molar to the } \mathrm{S} \text { vertical plane }\end{array}$ \\
\hline
\end{tabular}




\begin{tabular}{|c|c|}
\hline U6-SN $\left({ }^{\circ}\right)$ & $\begin{array}{l}\text { The angle formed between the long axis of maxillary first } \\
\text { permanent molar to the SN line }\end{array}$ \\
\hline U6-FHP $\left({ }^{\circ}\right)$ & $\begin{array}{l}\text { The angle formed between the long axis of maxillary first } \\
\text { permanent molar to the FHP. }\end{array}$ \\
\hline $\mathrm{IMW}(\mathrm{mm})$ & $\begin{array}{l}\text { Distance from center of occlusal surface of right first } \\
\text { permanent molar to center of occlusal surface of left first } \\
\text { permanent molar }\end{array}$ \\
\hline U6-MSP $\left({ }^{\circ}\right)$ & $\begin{array}{l}\text { The anterior angle formed by MBc6-DPc6 line of the maxillary } \\
\text { first permanent molar and midsagittal plane. }\end{array}$ \\
\hline \multicolumn{2}{|c|}{ Upper central incisor } \\
\hline U1-S Ver (mm) & $\begin{array}{l}\text { The distance from incisal edge of upper right central incisor to } \\
\text { the } S \text { vertical plane }\end{array}$ \\
\hline U1-SN $\left({ }^{\circ}\right)$ & $\begin{array}{l}\text { The angle formed between the long axis of the maxillary } \\
\text { incisor and the } \mathrm{SN} \text { plane }\end{array}$ \\
\hline $\mathrm{U} 1-\mathrm{FHP}\left({ }^{\circ}\right)$ & $\begin{array}{l}\text { The angle formed between the long axis of the maxillary } \\
\text { incisor and the FHP. }\end{array}$ \\
\hline U1/L1 ( $\left.{ }^{\circ}\right)$ & Interincisal angle \\
\hline
\end{tabular}

Upper first premolar

\begin{tabular}{|c|c|}
\hline U4-S Ver $(\mathrm{mm})$ & $\begin{array}{r}\text { The distance from buccal cusp tip of upper right first premolar } \\
\text { to the S vertical plane }\end{array}$ \\
\hline U4-SN $\left(^{\circ}\right)$ & $\begin{array}{r}\text { The angle formed between the long axis of maxillary first } \\
\text { premolar to the SN line }\end{array}$ \\
\hline U4-FHP $\left(^{\circ}\right)$ & $\begin{array}{r}\text { The angle formed between the long axis of maxillary first } \\
\text { premolar to the FHP. }\end{array}$ \\
\hline IPW4 $(\mathrm{mm})$ & $\begin{array}{r}\text { Distance from center of occlusal surface of right first premolar } \\
\text { to center of occlusal surface of left first premolar }\end{array}$ \\
\hline $\mathrm{U} 4-\mathrm{MSP}\left({ }^{\circ}\right)$ & $\begin{array}{r}\text { The anterior angle formed by Bc4-Pc4 line of the maxillary } \\
\text { first premolar and midsagittal plane. }\end{array}$ \\
\hline
\end{tabular}

Upper second premolar

\begin{tabular}{|c|c|}
\hline U5-S Ver (mm) & $\begin{array}{l}\text { The distance from buccal cusp tip of upper right second } \\
\text { premolar to the } S \text { vertical plane }\end{array}$ \\
\hline U5-SN $\left(^{\circ}\right)$ & $\begin{array}{l}\text { The angle formed between the long axis of maxillary second } \\
\text { premolar to the SN line }\end{array}$ \\
\hline U5-FHP $\left(^{\circ}\right)$ & $\begin{array}{l}\text { The angle formed between the long axis of maxillary second } \\
\text { premolar to the FHP. }\end{array}$ \\
\hline IPW5 (mm) & $\begin{array}{l}\text { Distance from center of occlusal surface of right second } \\
\text { premolar to center of occlusal surface of left second premolar }\end{array}$ \\
\hline U5-MSP $\left({ }^{\circ}\right)$ & $\begin{array}{l}\text { The anterior angle formed by Bc5-Pc5 line of the maxillary } \\
\text { second premolar and midsagittal plane. }\end{array}$ \\
\hline \multicolumn{2}{|l|}{ Soft tissue } \\
\hline Ls-Eline (mm) & Linear distance from Ls to E-line \\
\hline Li-Eline (mm) & Linear distance from Li to E-line \\
\hline $\operatorname{NLA}\left({ }^{\circ}\right)$ & Nasolabial angle \\
\hline
\end{tabular}




\section{Statistical analysis}

Statistical analysis was performed by Microsoft Office 2010 (Excel) and Statistical Package for Social Science SPSS version 20 (SPSS Inc, Chicago, III). Numerical data were presented as mean and standard deviation (SD) values. The data was explored for normality using Shapiro-Wilk tests which indicated normal distribution. Thus parametric test was applied for data analysis; Paired sample t-test was used to compare between pretreatment and postdistalization periods. The statistical significance level was set at $\mathrm{P} \leq 0.05$. Intraobserver reliability (agreement) was measured using Intra-Class correlation coefficient (ICC).

\section{Results}

The paired sample t-test was used to compare between the pretreatment and the postdistalization treatment effects of the Skeletal
Frog appliance for each variable. Regarding the skeletal measurements in the anteroposterior dimension there was a statistically significant decrease of sella-nasion-B point (SNB), and nasion-pogonion-Frankfort plane (N-Pog-FHP) angles by $0.89^{\circ}$ and $1.26^{\circ}$ respectively ( $p £$ $0.05)$. Whereas in the vertical dimension there was a statistically significant increase in lower anterior facial height as indicated by anterior nasal spine to menton (ANS-Me), and mandibular plane to sella-nasion (MP-SN) angles by $1.1 \mathrm{~mm}$ and $2.01^{\circ}$ respectively ( $p £$ 0.05). The transverse skeletal measurements showed a statistically significant decrease of the maxillary base width between JR-JL by 2.17mm ( $p £ 0.05$ ) (Table 2).

Table 2. Comparison of the skeletal changes induced by Skeletal Frog appliance before (T1) and after distalization (T2)

\begin{tabular}{|c|c|c|c|c|c|c|}
\hline \multirow[t]{2}{*}{ Variable } & \multicolumn{2}{|c|}{$\begin{array}{l}\text { Pretreatment ( } \mathrm{T} 1) \\
\text { group }\end{array}$} & \multicolumn{2}{|c|}{ Post-distalization (T2) } & \multirow[b]{2}{*}{ Mean difference } & \multirow[t]{2}{*}{$P$ value } \\
\hline & Mean & SD & Mean & SD & & \\
\hline SNA $\left({ }^{\circ}\right)$ & 82.70 & \pm 0.61 & 82.90 & \pm 1.80 & -0.2 & 0.729 \\
\hline $\operatorname{SNB}\left({ }^{\circ}\right)$ & 79.69 & \pm 0.95 & 78.80 & \pm 0.82 & 0.89 & $0.024^{*}$ \\
\hline $\operatorname{ANB}\left({ }^{\circ}\right)$ & 3.59 & \pm 1.14 & 4.70 & \pm 1.98 & -1.11 & 0.084 \\
\hline N-Pog-FHP $\left({ }^{\circ}\right)$ & 88.28 & \pm 1.24 & 87.02 & \pm 1.23 & 1.26 & $0.018^{*}$ \\
\hline ANS-Me (mm) & 60.24 & \pm 1.40 & 61.34 & \pm 1.10 & -1.1 & $0.038^{*}$ \\
\hline $\operatorname{MP}-\mathrm{SN}\left({ }^{\circ}\right)$ & 34.71 & \pm 1.08 & 36.72 & \pm 0.87 & -2.01 & $0.004^{*}$ \\
\hline $\operatorname{MP}-P P\left({ }^{\circ}\right)$ & 23.61 & \pm 1.97 & 25.65 & \pm 1.11 & -2.04 & $0.023^{*}$ \\
\hline OP-PP $\left({ }^{\circ}\right)$ & 7.83 & \pm 1.84 & 10.04 & \pm 1.95 & -2.21 & $0.018^{*}$ \\
\hline $\operatorname{OP}-M P\left({ }^{\circ}\right)$ & 8.02 & \pm 2.09 & 10.17 & \pm 2.01 & -2.15 & 0.075 \\
\hline J R-J L (mm) & 65.66 & \pm 2.11 & 63.49 & \pm 2.42 & 2.17 & $0.048^{*}$ \\
\hline
\end{tabular}

Values are presented as mean \pm standard deviation.

See Table 1 for abbreviations and definitions of each landmark or measurement. Paired-samples ttest was used; statistically significant at $p<0.05$. 
Concerning the changes in dental measurements the maxillary first molar (U6) revealed a statistically significant decrease in the anteroposterior position which was displayed by maxillary first molar long axis to the sella-nasion plane (U6-SN) and maxillary first molar long axis to the Frankfort horizontal plane (U6-FHP) angles by $9.02^{\circ}$ and $9.16^{\circ}$ respectively ( $p £$ 0.05). The distance from mesiobuccal cusp tip of upper first permanent molar to the Sella vertical plane (U6-S Ver) decreased by $4.14 \mathrm{~mm}$. The vertical position of the maxillary first permanent molar to sellanasion U6-SN) decreased by $2.03 \mathrm{~mm}$. Whereas the maxillary inter-molar width increased by $2.41 \mathrm{~mm}$. The maxillary right and left first molar exhibited significant rotation $4.33^{\circ}$ and $4.83^{\circ}$ respectively as indicated by a line connecting the mesiobuccal cusp tip to distopalatal cusp tip to midsagittal plane (MSP) (Table 3).

Table 3. Comparison of the maxillary first molar and soft tissue changes induced by Skeletal Frog appliance before (T1) and after distalization (T2)

\begin{tabular}{|c|c|c|c|c|c|c|}
\hline \multirow[t]{2}{*}{ Variable } & \multicolumn{2}{|c|}{$\begin{array}{l}\text { Pretreatment (T1) } \\
\text { group }\end{array}$} & \multicolumn{2}{|c|}{ Post-distalization (T2) } & \multirow[b]{2}{*}{ Mean difference } & \multirow[t]{2}{*}{$P$ value } \\
\hline & Mean & SD & Mean & SD & & \\
\hline U6-S Ver (mm) & 43.95 & \pm 2.12 & 39.81 & \pm 2.14 & 4.14 & $0.001 *$ \\
\hline U6-SN $\left({ }^{\circ}\right)$ & 71.05 & \pm 1.82 & 62.03 & \pm 2.47 & 9.02 & $<0.001 *$ \\
\hline U6-FHP $\left({ }^{\circ}\right)$ & 82.9 & \pm 2.2 & 73.74 & \pm 2.52 & 9.16 & $<0.001^{*}$ \\
\hline $\mathrm{IMW}(\mathrm{mm})$ & 44.9 & \pm 4.33 & 47.31 & \pm 2.67 & -2.41 & $0.025^{*}$ \\
\hline RU6-MSP $\left({ }^{\circ}\right)$ & 28.23 & \pm 3.5 & 23.9 & \pm 7.1 & 4.33 & $0.026^{*}$ \\
\hline LU6-MSP $\left({ }^{\circ}\right)$ & 26.98 & \pm 4.6 & 22.13 & \pm 2.8 & 4.85 & $0.041^{*}$ \\
\hline Ls-Eline (mm) & 1.25 & \pm 1.60 & 1.12 & \pm 2.97 & 0.13 & 0.928 \\
\hline Li-Eline (mm) & 3.94 & \pm 1.85 & 3.38 & \pm 1.72 & 0.56 & 0.4343 \\
\hline $\operatorname{NLA}\left({ }^{\circ}\right)$ & 115.66 & \pm 2.84 & 118.53 & \pm 3.41 & -2.87 & $0.047^{*}$ \\
\hline
\end{tabular}

Values are presented as mean \pm standard deviation.

See Table 1 for abbreviations and definitions of each landmark or measurement. Paired-samples ttest was used; statistically significant at $p<0.05$.

Regarding the maxillary first and second interpremolar width increased by $0.8 \mathrm{~mm}$ and $0.68 \mathrm{~mm}$ respectively. Whereas insignificant rotation of maxillary right and left first and second premolars were detected. There was a decrease in the anteroposterior position of the maxillary first and second premolars in relation to Sella vertical line by $1.89 \mathrm{~mm}$ and $2.8 \mathrm{~mm}$ respectively, significant decrease in the anteroposterior position in relation to $\mathrm{SN}$ and FHP $5.01^{\circ}$ and $5.16^{\circ}$ respectively ( $p £ 0.05$ ), and insignificant increase in the vertical positions as well (Table 4). 
Table 4. Comparison of the anchorage teeth changes induced by Skeletal Frog appliance before (T1) and after distalization (T2)

\begin{tabular}{|c|c|c|c|c|c|c|}
\hline \multirow[t]{2}{*}{ Variable } & \multicolumn{2}{|c|}{$\begin{array}{l}\text { Pretreatment (T1) } \\
\text { group }\end{array}$} & \multicolumn{2}{|c|}{ Post-distalization (T2) } & \multirow[b]{2}{*}{ Mean difference } & \multirow[t]{2}{*}{$P$ value } \\
\hline & Mean & SD & Mean & SD & & \\
\hline U1-S Ver (mm) & 76.44 & \pm 1.33 & 75.54 & \pm 2.83 & 0.9 & 0.219 \\
\hline U1-SN $\left({ }^{\circ}\right)$ & 109.6 & \pm 3.45 & 108.43 & \pm 4.83 & 1.17 & 0.474 \\
\hline U1-FHP $\left({ }^{\circ}\right)$ & 121.45 & \pm 3.66 & 120.14 & \pm 4.7 & 1.31 & 0.401 \\
\hline $\mathrm{U} 1 / \mathrm{L} 1\left(^{\circ}\right)$ & 112.65 & \pm 2.99 & 115.89 & \pm 2.43 & -3.24 & $0.023 *$ \\
\hline U4-S Ver (mm) & 54.75 & \pm 3.06 & 52.86 & \pm 2.45 & 1.89 & 0.169 \\
\hline U4-SN $\left({ }^{\circ}\right)$ & 83.1 & \pm 1.76 & 80.37 & \pm 2.58 & 2.73 & $0.05^{*}$ \\
\hline U4-FHP $\left({ }^{\circ}\right)$ & 94.95 & \pm 2.72 & 91.65 & \pm 1.98 & 3.3 & $0.033^{*}$ \\
\hline IPW4 (mm) & 39.68 & \pm 0.97 & 40.48 & \pm 1.45 & -0.8 & 0.233 \\
\hline $\mathrm{R} \cup 4-\mathrm{MSP}\left({ }^{\circ}\right)$ & 76.22 & \pm 4.1 & 78.73 & \pm 5.4 & -2.51 & 0.65 \\
\hline LU4-MSP( $\left.{ }^{\circ}\right)$ & 81.95 & \pm 2.9 & 83.87 & \pm 6.1 & -1.92 & 0.24 \\
\hline U5-S Ver (mm) & 49.58 & \pm 2.38 & 46.78 & \pm 1.42 & 2.8 & $0.026 *$ \\
\hline U5-SN $\left({ }^{\circ}\right)$ & 79.31 & \pm 1.57 & 74.3 & \pm 2.31 & 5.01 & $0.002^{*}$ \\
\hline $\mathrm{U} 5-\mathrm{FHP}\left({ }^{\circ}\right)$ & 91.16 & \pm 1.92 & 86 & \pm 2.65 & 5.16 & $0.003^{*}$ \\
\hline IPW5 (mm) & 33.85 & \pm 1.03 & 34.53 & \pm 1.39 & -0.68 & 0.32 \\
\hline $\mathrm{RU5}-\mathrm{MSP}\left({ }^{\circ}\right)$ & 76.44 & \pm 8.8 & 80.26 & \pm 9.7 & -3.82 & 0.098 \\
\hline LU5-MSP $\left({ }^{\circ}\right)$ & 76.84 & \pm 6.8 & 79.7 & \pm 8 & -2.86 & 0.12 \\
\hline
\end{tabular}

Values are presented as mean \pm standard deviation.

See Table 1 for abbreviations and definitions of each landmark or measurement. Paired-samples ttest was used; statistically significant at $p<0.05$.

As for maxillary central incisors they showed that there were statistically insignificant decrease in the anteroposterior position for both angular and linear measurements by $1.17^{\circ}$ and $0.9 \mathrm{~mm}$. Maxillary central incisors displayed insignificant increase in the vertical position by $0.64 \mathrm{~mm}$ (U1-SN). Whereas the interincisal angle which is the angle between the upper central incisor long axis to lower incisor long axis (U1/L1) revealed a statistically significant increase by $3.24^{\circ}$ ( $p £$ 0.05) (Table 4). The soft tissue measurement showed that, there were statistically significant increase in the nasolabial angle by $2.87^{\circ}(p £$ 0.05) (Table 3).

\section{Discussion}

Many treatment alternatives have been proposed for the treatment of class II division 1 malocclusions, among which are maxillary 
molar distalization that is gaining more popularity. Various methods are implemented for maxillary molar distalization such as headgear which is an effective extraoral appliance yet its drawbacks are patient compliance and esthetic concerns. In an attempt to overcome these disadvantages many fixed intraoral distalizers were introduced. However, these tooth-borne appliances posed problems regarding anchorage loss, increase of overjet, jeopardizing molar stability, and prolongation of treatment duration. Recently the advent of TADs paved the way for researchers to combine them with various tooth-borne distalizing appliances such as the Skeletonized distal jet ${ }^{20}$ and the Skeletal Frog ${ }^{19}$ to avoid the disadvantages of the conventional intramaxillary distalizers.

In 2011 Ludwig et al. ${ }^{19}$ was the first to introduce the Skeletal Frog distalizer. One of the major setbacks of their study was that it was conducted on only two case reports, in addition to the lack of evaluation of the skeletal, dentoalveolar and soft tissue effects. Thus the aim of our study was to assess the effects of the Skeletal Frog on a larger sample size (25 subjects) and the variables were evaluated three dimensionally utilizing the CBCT which to the best of our knowledge was not addressed.

All subjects in this study exhibited bilateral molar relationship since the original assembly of the Skeletal Frog was designed for bilateral ditalization $^{21}$, in addition to avoiding the implementation of asymmetric distalizing mechanics which might have an adverse effect on the skeletal, dentoalveolar and soft tissue measurements.

The integration of two TADs placed paramedian $3 \mathrm{~mm}$ from the midsagittal suture prevented the possible developmental disturbances of the midpalatal sutures. Insertion of TDAs $6 \mathrm{~mm}$ behind the incisive papillae ensured adequate bone thickness thus providing biomechanical stability of the TADs and a stable four-point support for the appliance $^{19}$. Since the TADs were inserted palatally where there was a reduced possibility of root injury, thus their selected diameters were $2 \mathrm{~mm}$ which in turn increases stability due to the increase in cortical bone contact. Whereas, the length was $6 \mathrm{~mm}$ to prevent the possibility of perforation of the nasal cavity.

Skeletal, dental, and soft tissue measurements implemented in this study were performed on $3 \mathrm{D}$ volumetric analysis obtained from CBCT scan on a computer software program. The 3D volumetric analysis had an advantage over 2D analysis as a more accurate measurement due to the lack of bilateral structure superimposition and reduced possibility of errors in identification ${ }^{5,22}$.

The associated skeletal changes in the sagittal plane in this study displayed a decrease in SNB angle $0.89^{\circ}$ and N-Pog/FHP $1.26^{\circ}$ while in the vertical plane the lower anterior facial height showed an insignificant increase which was evident in the posterior rotation of the mandible as indicated by MP/SN, OP/PP, $\mathrm{OP} / \mathrm{MP}$, and $\mathrm{OP} / \mathrm{FH}$ this is concurrent with the findings of Burhan?

The amount of distalization in studies based on bone-borne anchorage appliances, was between 1.3 and $6.4 \mathrm{~mm}^{2,4,14,15}$. Whereas, studies that involved tooth-borne appliances such as the dual force distalizers supported by miniimplants or pendulums attributed to a higher degree of molar distalization ${ }^{16}$. In our study, along the sagittal plane, the Skeletal Frog appliance displayed a significant distalization of the maxillary first molar of $4.14 \mathrm{~mm}$. The molar distalization was similar to that reported by Mujia et. al., $(4.25 \mathrm{~mm}),{ }^{5}$ Bayram et al. $(4 \mathrm{~mm})^{3}$, Nalcaci et al. $^{4}$ and Gelgör et al. ${ }^{2}$ whom distalized molars via TADs with open coil springs and TADs supported TPAs and 
springs by an average of ( $3.95 \pm 1.35 \mathrm{~mm})$, and $(3.9 \pm 1.6 \mathrm{~mm})$ respectively. Yet, the amount of distalization was slightly smaller than the findings of Burhan $(5.51 \mathrm{~mm})^{7}$. These dissimilarities might be due to the differences in appliance designs, longer treatment durations, and sample criteria.

Maxillary molar tipping in this study was $9.16^{\circ}$ which is consistent to that obtained by; Kircelli et al. ${ }^{14}$ with bone-anchored pendulum appliance $\left(10.9^{\circ}\right)$, Bussick and McNamara ${ }^{23}$ with the Pendulum appliance $\left(10.6^{\circ}\right)$, and Patel et al. ${ }^{24}$ with Jones jig $\left(9.54^{\circ}\right)$. However, less values for molar tipping where shown by; Burhan $^{7}$ when combining the frog appliance with/without headgear $\left(4.96^{\circ}\right.$ and $1.25^{\circ}$ respectively), Chiu et al. ${ }^{25}$ with the distal jet $\left(5^{\circ}\right)$, Kinzinger et al. $^{26}$ with the pendulum $\mathrm{K}$ $\left(4.65^{\circ}\right)$, and Bayram et al. ${ }^{3}$ with the Frog appliance $\left(3^{\circ}\right)$. These dissimilarities might be the result of the amount of molar distalization, differences in appliance designs, and the full eruption of the maxillary second molar which has been reported in the literature to contribute to a significant amount of molar tipping 5 . Furthermore, tipping in our research can be due to the position of the Skeletal Frog screw which was $10-12 \mathrm{~mm}$ below the occlusal plane close to the center of resistance of the maxillary first molar rather than being placed close to the center of resistance of the second molar which is at $9 \mathrm{~mm}$ below the occlusal plane ${ }^{5}$.

Numerous authors displayed molar intrusion in their studies with bone-borne distalizers ${ }^{14,16,27}$. Regarding the vertical plane the maxillary molar showed intrusion of $2.46 \mathrm{~mm}$ that might be due to the low position of the double-bend of the stainless steel spring in relation to the level of the band sheath which in turn causes the line of action of the force to pass apical to the molar center of resistance thus, intruding the molars. Molar distalization is associated with their divergence along the arch form natural shape as suggested by Bolla et al. ${ }^{6}$ The transverse changes in the intermolar width in the present study unveiled an increase of $2.41 \mathrm{~mm}$ which is consistent with the findings of Mujia et $\mathrm{al}^{5}$. $(2.87 \mathrm{~mm})$ and Miresmaeili et $\mathrm{al}^{12}$. $(2.9 \mathrm{~mm})$.

Presented in the current study is the distobuccal rotation of the maxillary first molar by $4.3^{\circ}$ and $4.85^{\circ}$ for the right and left sides, molar rotation could not be prevented since the point of force application is palatal, farther from the molar center of resistance. Buffering measures such as toe-in was not enforced in this study as it creates a complicated multi-couple system that is strenuous to control in addition to friction ${ }^{18}$. These findings are in agreement with Uzuner et al. ${ }^{28}$ where the maxillary molar exhibited a distobuccal rotation of $5.9^{\circ}$ and $4.4^{\circ}$ for the right and left sides with the Frog appliance.

One of the most characteristic aspects of Skeletal Frog in this research is the simultaneous distal movement and distal tipping of the premolars by $1.9 \mathrm{~mm}$ and $2.7^{\circ}$ for the first premolar and $2.8 \mathrm{~mm}$ and $5^{\circ}$ for the second premolar respectively. In addition to extrusion of the first and second premolar by $0.56 \mathrm{~mm}$ and $0.8 \mathrm{~mm}$ respectively. This is due to the Skeletal Frog design where the premolars are not included in the anchor unite therefore, they are free to drift. This is advantageous in two aspects; First the new molar position would not be jeopardized since the unnecessary round tripping of the premolars has been avoided through the phenomena of driftodontics. Secondly the first and second interpremolar widths increased by $0.8 \mathrm{~mm}$ and $0.68 \mathrm{~mm}$ respectively, this could be attributed to their freedom to drift distally which is in agreement with Uzuner et al. ${ }^{28}$ whom recorded significant expansion in premolar region with the Karads integrated distalizing system. 
Fudalej and Antoszewska ${ }^{29}$ in a systematic review suggested that implementation of temporary skeletal anchorage devices during molar distalization could help avoid labial movement of the maxillary incisors. The findings in current study presented retroclination of the maxillary incisors by $1.3^{\circ}$ (U1/FH) and retrusion by $0.9 \mathrm{~mm}$ (U1-SVer) in addition to increase in the interincisal angle by $3.24^{\circ}$. This might be accredited to the freedom of the incisors therefore, causing the anterior crowding to spontaneously solve out by the stretched trans-septal fibers and the effect of the upper lip. As a consequence, the nasolabial angle showed an increase by $2.87^{\circ}$ indicating retrusion of the upper lip which is in harmony with Papadopoulos et al. ${ }^{30}$ thus improving facial profile.

\section{Conclusion}

The Skeletal Frog appliance is a fixed skeletal palatal intraoral appliance that has revealed substantial agreement as a means for treating Class II division 1 malocclusions via efficacious distalization of the maxillary molars with the second molars fully erupted. The Skeletal Frog appliance is a simple and hygienic distalizer. It produces maxillary molar distalization without any undesirable side effects on the premolars and incisors. It is associated with spontaneous distal drift of the premolars via driftodontics, in addition to unraveling of the anterior crowding through stretching of the trans-septal fibers thus, permitting leveling and alignment of the maxillary arch to occur simultaneously during the molar distalization. Moreover, the CBCT images demonstrated exactly and veraciously the three-dimensional structures. Therefore, creating a reliable and accurate method for three-dimensional analysis.

\section{Reference}

1. Angle E.H: Treatment of Malocclusion of the Teeth. 7th ed. Philadelphia, SS White Dental Manufacturing Co., 1907.

2. Gelgör IE, Büyükyilmaz T, Karaman AI, Dolanmaz D, Kalayci A. Intraosseous screw-supported upper molar distalization. Angle Orthod 2004;74:838-50.

3. Bayram M, Nur M, Kilkis D. The frog appliance for upper molar distalization: a case report. Korean J Orthod 2010;40:50-60.

4. Nalcaci R, Bicakci AA, Ozan F. Noncompliance screw supported maxillary molar distalization in a parallel manner. Korean J Orthod 2010;40:250-9.

5. Mujia L, Xiaoxia S, Yang L, Xianglin $\mathrm{L}$, et al. Cone-beam computed tomographyguided three-dimensional evaluation of treatment effectiveness of the Frog appliance. Korean J Orthod 2019;49(3):161-169.

6. Bolla E, Muratore F, Carano A, Bowman SJ. Evaluation of maxillary molar distalization with the distal jet: a comparison with other contemporary methods. Angle Orthod 2002;72:481-94.

7. Burhan AS. Combined treatment with headgear and the Frog appliance for maxillary molar distalization: a randomized controlled trial. Korean J Orthod 2013;43:101-9.

8. Kinzinger GS, Eren M, Diedrich PR. Treatment effects of intraoral appliances with conventional anchorage designs for noncompliance maxillary molar distalization: a literature review. Eur J Orthod 2008;30:55871.

9. Mavropoulos A, Karamouzos A, Kiliaridis S, Papadopoulos MA. Efficiency of noncompliance simul- taneous first and second upper molar distalization:a three-dimensional tooth movement analysis. Angle Orthod 2005; 75:532-9.

10. Miresmaeili A, Sajedi A, Moghimbeigi A, Farhadian N. Three-dimensional analysis of 
the distal movement of maxillary $1^{\text {st }}$ molar in patients fitted with mini-implant-aided transpalatal arches. Korean J Orthod 2015;45(5):236-244.

11. Nalcaci R, Kocoglu-Altan AB, Bicakci AA, Ozturk F, Babacan H. A reliable method for evaluating upper molar distalization: Superimposition of three-dimensional digital models. Korean J Orthod 2015;45:82-8.

12. Kircelli BH, Pektaş ZO, Kircelli C. Maxillary molar distalization with a boneanchored pendulum appliance. Angle Orthod 2006;76:650-9.

13. Sar C, Kaya B, Ozsoy O, Özcirpici AA. Comparison of two implant supported molar distalization systems. Angle Orthod 2013;83:460-7.

14. Escobar SA, Tellez PA, Moncada CA, Villegas CA, Latorre CM, Oberti G. Distalization of maxillary molars with the bone-supported pendulum: a clinical study. Am J Orthod Dentofacial Orthop 2007; 131:545-9.

15. Yamada K, Kuroda S, Deguchi T, Takano-Yamamoto T, Yamashiro T. Distal movement of maxillary molars using miniscrew anchorage in the buccal interradicular region. Angle Orthod 2009;79:78-84.

16. Kinzinger GS, Gülden N, Yildizhan F, Diedrich PR. Efficiency of a skeletonized distal jet appliance supported by miniscrew anchorage for noncompliance maxillary molar distalization. Am J Orthod Dentofacial Orthop 2009;136:578-86.

17. Ludwig B, Glasl B, Kinzinger GS, Walde KC, Lisson JA. The skeletal frog appliance for maxillary molar distalization. J Clin Orthod 2011;45:77-84; quiz 91.

18. Kinzinger, G. and Diedrich, P.: A minimized Distal Jet with miniscrew anchorage for non-compliance distal movement of maxillary molars, Kieferorthop. 21:243-251, 2007.
19. Walde, K.C.: The Simplified Molar Distalizer, J. Clin. Orthod. 37:616-619, 2003.

20. Gracco A, Lombardo L, Cozzani M, Siciliani G. Quantitative evaluation with CBCT of palatal bone thickness in growing patients, Prog. Orthod. 7:164-174, 2006.

21. Bussick TJ, McNamara JA Jr. Dentoalveolar and skeletal changes associated with the pendulum appliance. Am J Orthod Dentofacial Orthop 2000; 117:333-43.

22. Patel MP, Janson G, Henriques JF, de Almeida RR, de Freitas MR, Pinzan A, et al. Comparative distalization effects of Jones jig and pendulum appliances. Am J Orthod Dentofacial Orthop 2009;135:336-42.

23. Chiu PP, McNamara JA Jr, Franchi L. A comparison 2 of two intraoral molar distalization appliances: distal jet versus pendulum. Am J Orthod Dentofacial Orthop 2005;128:353-65.

24. Kinzinger GS, Gross U, Fritz UB, Diedrich PR. Anchorage quality of deciduous molars versus premolars for molar distalization with a pendulum appliance. Am J Orthod Dentofacial Orthop 2005; 127:314-23.

25. Kang JM, Park JH, Bayome M, Oh M, Park CO, Kook YA, et al. A three-dimensional finite element analysis of molar distalization with a palatal plate, pendulum, and headgear according to molar eruption stage. Korean J Orthod 2016;46:290-300.

26. Uzuner FD, Kaygisiz E, Unver F, Tortop T. Comparison of transverse dental changes induced by the palatally applied Frog appliance and buccally applied Karad's integrated distalizing system. Korean J Orthod 2016;46:96-103.

27. Fudalej P, Antoszewska J. Are orthodontic distalizers reinforced with the temporary skeletal anchorage devices effective? Am J Orthod Dentofacial Orthop 2011;139:722-9. 
28. Papadopoulos MA, Melkos AB, appliance: a randomized controlled trial. Am J Athanasiou AE. Noncompliance maxillary Orthod Dentofacial Orthop 2010;137:586. e1molar distalization with the first class 586.e13 